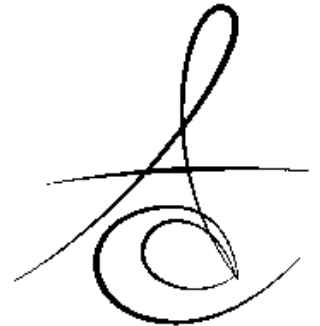

Makale Kodu/Article code: 1550

Makale Gönderilme tarihi: 20.02.2014

Kabul Tarihi: 28.04.2014

\section{EGE BÖLGESİ ÇOCUKLARINDA KONJENİTAL DAİMİ DİŞ EKSİKLİĞİ PREVALANSININ ARAŞTIRILMASI}

\section{PREVALENCE OF CONGENITALLY MISSING PERMANENT TEETH IN AEGEAN REGION CHILDREN}

\author{
Dr. Ümit CANDAN* \\ Dr. Özlem KIPÇAK ** \\ Doç. Dr. M.Sinan EVCİL***
}

\section{ÖZET}

Amaç: Bu çalışmanın amacı, üçüncü büyük azı dişleri dışındaki, daimi dişlerin konjenital olarak eksikliğinin cinsiyet ve lokalizasyona göre prevalansını ve dağıımını belirlemektir.

Gereç ve Yöntem: Bu çalışmada Ocak 2012 ile Haziran 2013 tarihleri arasında İzmir Eğitim Diş Hastanesine başvuran 8-22 yaş arasında 1388 (814 kadın, 574 erkek) hastadan alınan panoramik radyografileri konjenital diş eksikliği açısından retrospektif olarak değerlendirildi. Yapılan incelemede standardize bir araştırma formu kullanıldı. Anamnezde ve klinik kayıtlarda diş çekimi, dudak damak yarığı ve sistemik rahatsızığı olan hastalar çalışmadan çıkarıldı. Olgular cinsiyet, diş eksikliğinin lokalizasyonu yönünden araştırıldı. Elde edilen veriler istatistiksel olarak Chi-Square testi ve t testi ile değerlendirildi.

Bulgular: 1388 panoromik röntgende, 110 hastada (73'ü kadın, 37'si erkek) 121 adet konjenital olarak diş eksikliği saptandı. Çalışmamızda daimi diş eksikliği prevelansı \%7.9 (kızlarda \% 8.9, erkeklerde \%6.4) bulundu. En sık diş eksikliği gözlenen dişler sırasıyla; alt ikinci küçük azı, üst ikinci küçük azı ve üst yan kesici diş olarak tespit edildi. Konjenital daimi diş eksikliği alt çenede üst çeneye göre daha fazla görülmesine rağmen, istatistiksel olarak anlamlı bir fark bulunmadı.

Sonuç: Sonuç olarak; konjenital diş eksiklerinin teşhis ve tedavisinde, detaylı klinik ve radyolojik muayenin rolü büyük olmakla beraber konjenital diş eksikliğinin erken teşhis ile tespit edilmesi tedavi planlaması açısından da önem taşımaktadır.

Anahtar Kelimeler: Konjenital diş eksikliği, prevelans, retrospektif çalışma

\section{ABSTRACT}

Purpose: The purpose of this study was to evaluate the prevalance and distribution of congenitally missing teeth according to gender and localization, excluding the third molar.

Material and Methods: This study was evaluate retrospective examination on panoramic radiographs of 1388 patients (814 females and 574 males) between the ages 8 and 22 years who referred to Izmir Dental Education Hospital from January 2012 to June 2013. This study was used a standart survey form. The clinical examination and patient's history with tooth extraction, cleft lip and palate, systemic disorder were excluded. The cases were evaluated according to gender and localization. The data were statistically evaluated by Chi-Square and t-test.

Results: 121 congenitally missing teeth in 110 patients (73 females, 37 males) were found on 1388 panoromic radiographs. The prevalence of congenitally missing permanent teeth was $7.9 \%$ The most commonly missing teeth were the mandibular second premolars, followed by the maxillary second premolars, and the maxillary lateral incisors. Congenitally permanent missing teeth were observed more than mandibula to maxilla but there were no statistically significant difference between the jaws.

Conclusion: As a conclusion, although the role of detailed clinical and radiographic examination is important at the the determination of congenitally missing tooth, early diagnosis is also prominent in terms of practice of treatments planning.

Key Words: Congenitally missing teeth, prevalence, retrospective study

*İzmir Eğitim Diş Hastanesi Pedodonti Uzmanı

**İzmir Eğitim Diş Eğitim Hastanesi, Ağız, Diş ve Çene Radyolojisi Uzmanı

***İzmir Eğitim Diş Eğitim Hastanesi, Endodonti Uzmanı 


\section{GİRIŞ}

Dişlerin sayıları ile ilgili değişiklikler yaygındır ve bunları belirtmek için birçok terim kullanılmaktadır. Bir ya da daha fazla dişin gelişimsel olarak eksik olması hipodonti, üçüncü büyük azı dişleri dışında altı ya da daha fazla dişin konjenital eksikliği ise oligodonti; tüm dişlerin gelişimsel olarak eksik olması da anodonti olarak adlandırılmaktadır. ${ }^{1-3}$ Konjenital diş eksikliğinin etiyolojisi tam olarak bilinmemekle beraber hem genetik hem çevresel faktörlerin etkili olabileceği bildirilmektedir. ${ }^{4-7}$

Literatürde konjenital diş eksikliğinin prevalansı $\% 2.2$ ile \%36.5 arasında rapor edilmiştir. ${ }^{8-10,11} \mathrm{Bu}$ farklı prevelans değerlerinin nedeni incelendiğinde, yapılan çalışmalarda yaş grupları aralığının, muayene yöntemindeki farklılıkların buna neden olabileceği düşünülmektedir. ${ }^{10-14}$ Ayrıca çoğu çalışmada bölgesel ve ırksal farklılıkların elde edilen prevalans sonuçlarını ve dişlerin sayı dağılımlarını oldukça etkilediği de anlaşılmaktadır. ${ }^{14}$

Retrospektif çalışmalara göre, konjenital diş eksikliği en sık üçüncü molar dişlerde meydana gelmektedir. Bunu sırasıyla alt ikinci premolar, üst ikinci premolar ve üst lateral dişlerin yokluğunun takip ettiği tespit edilmiştir. ${ }^{12-15}$

Bu çalışmanın amacı, Ege Bölgesi çocuklarında konjenital daimi diş eksikliği prevelansı ve dağılımını belirlemektir.

\section{GEREÇ VE YÖNTEM}

Bu çalışma Ege Bölgesi çocuklarında konjenital daimi diş eksikliğini belirlemek amacıyla, Ocak 2012 ile Haziran 2013 tarihleri arasında İzmir Eğitim Diş Hastanesine başvurmuş 8-22 yaşları arasındaki toplam 1388 (814 kadın, 574 erkek) hastadan alınan panoramik radyografilerin tarandığı ve klinik kayıtlarının incelendiği retrospektif bir çalışma olarak yürütüldü. Yapılan incelemede standardize bir araştırma formu kullanıldı. Anamnezde ve klinik kayıtlarda diş çekimi, dudak-damak yarığı ve sistemik rahatsızlığı olan hastalar çalışmadan çıkarıldı. Ayrıca travma, periodontal hastalık veya çürük gibi etkene bağlı diş eksikliğine sebep olabilecek olgular da çalışmaya dahil edilmedi. Üçüncü büyük azı dişinin eksikliğinin dikkate alınmadığı ve kardeşlerin çalışma dışında bırakıldığı araştırmamızda, saptanan diş eksikliklerinin dişlere, diş sayılarına, cinsiyete ve çenelere göre dağılımı incelenmiştir. Elde edilen veriler istatistiksel olarak Chi-Square testi ve $\mathrm{t}$ testi ile değerlendirildi.

\section{BULGULAR}

Toplam 1388 hastadan alınan panoramik röntgende 110 hastada (73'ü kadın, 37'si erkek) 121 adet konjenital diş eksikliği saptandı. Çalışmamızda daimi diş eksikliği prevelansı \%7.9 olarak bulundu. Prevalans değerlerinin kadınlarda \% 8.9 (73 kadın) erkeklerde \%6.4 (37 erkek) olduğu ancak diş eksikliği açısından cinsiyete göre istatistiksel fark bulunmadığı tespit edildi ( $p>0.05$ ) (Tablo 1 ).

Konjenital olarak eksik olan 121 adet dişin 77 'si kadınlarda, 44'ü erkeklerde, 64'ü sağ, 57'si sol tarafta, 70'i alt çenede, 51'i üst çenede olduğu saptandı (Tablo 2).

En sık diş eksikliği gözlenen dişler sırasıyla; alt ikinci küçük azı, üst ikinci azı ve üst yan kesici diş olarak tespit edildi (Resim 1,2, 3). Konjenital daimi diş eksikliği alt çenede üst çeneye göre daha fazla görülmesine rağmen, istatistiksel olarak anlamlı bir fark bulunmadığı görüldü $(p>0,05)$. Diş eksikliği sıklıkla bir veya iki diş olarak gözlendi (Tablo 3 ).

Tablo 1. Diş eksikliği prevelans değerleri $(* p>0.05)$

\begin{tabular}{|l|l|l|l|}
\hline Diş eksikliği & Kadın* & Erkek* & Toplam \\
\hline Prevalans (\%) & 8.9 & 6.4 & 7.9 \\
\hline Sayı & 73 & 37 & 110 \\
\hline Toplam & 814 & 574 & 1388 \\
\hline
\end{tabular}

Tablo 2. Diş Eksikliğinin yarım çeneler, alt -üst çene ve cinsiyete göre dağılımı

\begin{tabular}{|l|l|l|l|l|l|}
\hline Cinsiyet & Diş sayıSI & Sağ & Sol & Alt & Üst \\
\hline Kadın & 77 & 40 & 37 & 42 & 35 \\
\hline Erkek & 44 & 24 & 20 & 28 & 16 \\
\hline Toplam & 121 & 64 & 57 & 70 & 51 \\
\hline
\end{tabular}

Tablo 3. Diş Eksikliği Olan Hastaların Eksik Diş Sayısına Göre Dağılımı

\begin{tabular}{|l|l|c|}
\hline Diş Eksikliği SayıSı & $\begin{array}{c}\text { Diş Eksikliği Olan } \\
\text { Hasta (n) }\end{array}$ & $\begin{array}{c}\text { Diş Eksikliği } \\
\text { Dağılımı (\%) }\end{array}$ \\
\hline 1 & 56 & 50.9 \\
\hline 2 & 37 & 33.6 \\
\hline 3 & 11 & 11 \\
\hline 4 & 6 & 5.45 \\
\hline
\end{tabular}




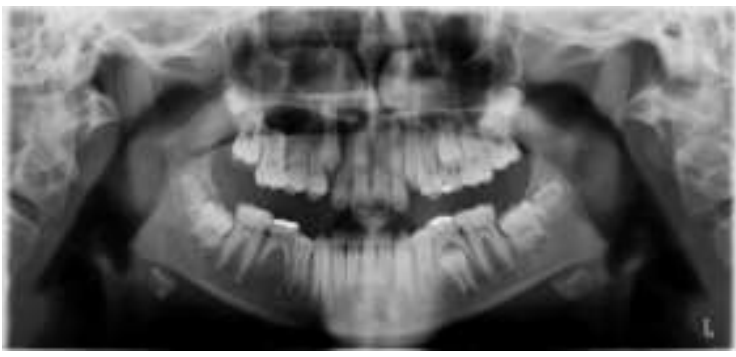

Resim 1. Sağ alt ikinci premolar diş eksikliğine sahip hastaya ait panoramik radyografi

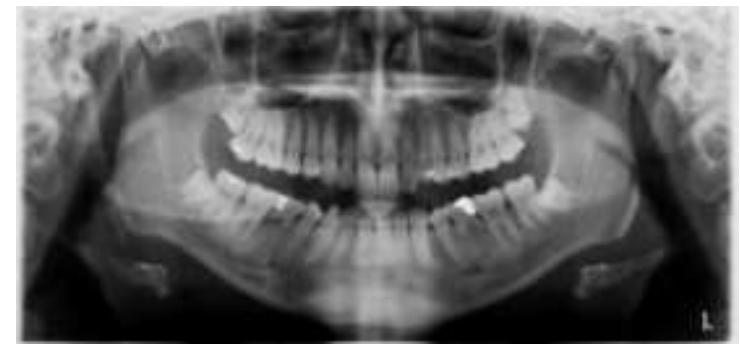

Resim 2. Alt sağ, sol ikinci premolar diş eksikliğine sahip hastaya ait panoramik radyografi

\section{TARTIŞMA}

Konjenital diş eksikliğinin etyolojisi hala tartışmalıdır. Enfeksiyon, travma, erken yaşta verilen kemoterapi ve radyoterapi, dudak-damak yarı̆ı̆, ektodermal displazi, down sendromu, düşük doğum ağırlığı, annenin yaşı, çoklu doğum, rubella, osteomiyelit ve kandidiyazis gibi enfeksiyonlar, thalidomide gibi ilaçların kullanımı gibi nedenlerin hipodontinin etyolojisinde etken olabileceği belirtilmiştir. ${ }^{1-6,9}$

Bu nedenle klinisyenler anamnez aşamasında hipodontiye neden olabilecek herhangi bir hastalık veya etkeni mutlaka araştırmalııır.

Konjenital diş eksikliğinin prevalans çalışmalarında farklılıklar olduğu görülmektedir. Bu farklılıkların nedeninin farklı metot ve yöntemlerden kaynaklanabileceği düşünülmektedir. Üçüncü molar dişlerin dahil edilip edilmemesi, hasta sayısı, örneklerin rastgele mi yoksa belli bir spesifik gruptan (ortodonti hastaları) $\mathrm{mI}$ seçildiği, örneklerin yaş aralığı gibi etkenler yapılan çalışmanın sonuçlarını etkilemektedir. Düşük sosyoekonomik düzeye sahip toplumlarda ağız hijyeninin yetersiz olmasına bağlı olarak çürük oluşumunun ve dişeti rahatsızlıkları bağı gelişen enfeksiyonların, konjenital diş eksikliğinin prevalansının daha yüksek çıkmasına neden olduğu bildirilmektedir. ${ }^{14}$

Hipodonti prevelansını belirlemeye yönelik olarak literatürde yayınlanan birçok çalışmaya rastlanılmasına rağmen Türk toplumunda yapılmış çalışma sayısının sınırlı olduğu görülmektedir. ${ }^{4,5,7,16}$ Bu çalışma, İzmir Eğitim Diş Hastanesine çevre il ve ilçelerden başvuran hastalardan oluşan geniş bir alanı kapsamaktadır. Araştırmamızda konjenital diş eksikliği prevelansı \%7.9 olarak bulundu. Cinsiyete göre dağıım değerlendirildiğinde kızlarda (\% 8.9), erkeklere oranla (\%6.4) daha fazla diş eksikliği gözlenmiştir. Bununla beraber aralarındaki farkın istatistiksel olarak anlamlı olmadığı görüldü $(p>0,05)$. Bu bulgumuz pek çok çalışma ile benzerlik göstermektedir. ${ }^{4-7,11,15-18}$

Çalışmamızda konjenital daimi diş eksikliği alt çenede üst çeneye göre daha sık görülmesine rağmen, diğer çalışmalarla benzerlikteki bu fark $(p>0,05)$ istatistiksel olarak anlamlı bulunmamışıı. ${ }^{9,12,13,16}$ Daha önce bildirilen çalışmalarla uyumlu bir şekilde bu çalışmada da konjenital diş eksikliğinin sol ve sağ yarım çeneler arasındaki dağılımının her iki cinsiyet arasında da farklılık göstermediği saptanmıştır. ${ }^{16,19,20}$

Çalışmamızda konjenital daimi diş eksikliğinin en sık gözlendiği dişlerin alt ikinci küçük azı dişleri olduğu tespit edilmiştir. Yapılan çalışmaların çoğu bulgumuz ile benzerlik göstermektedir. 2-5,14-16,18,19,21 Literatür incelendiğinde en $s ı$ eksikliği gözlenen dişlerin üst yan kesici dişler olduğunu bildiren çalışmalara da rastlanmaktadır. ${ }^{15,20}$

Konjenital daimi diş eksikliğinin araştırılmasında hem radyografilerden hem de klinik muayeneden yararlanılması tavsiye edilir. ${ }^{14,19,20}$ Sadece klinik muayene ile tespit edilen daimi diş eksikliğinin konjenital bir eksiklik olup olmadığının belirlenmesinde panoramik radyografiden yararlanılması gerekmektedir. Tüm dişlerin ve çene kemiğinin bir film üzerinde görüntüsünü sunan bu radyografiler erken teşhis ve tedavi olanağı sağlar. Bu sayede hem zamandan hem de tedavi maliyetlerinden tasarruf sağlanır.

\section{SONUÇ}

Konjenital daimi diş eksikliği ile ilgili yapılan çalışmalar incelendiğinde prevalans değerlerinin farklılıklar gösterdiği ancak çalışmamızdan elde edilen bulguların birçok çalışma ile benzerlik gösterdiği görülmektedir. Konjenital diş eksikliklerin teşhisinde, detaylı klinik ve radyolojik muayenenin rolü büyük olmakla beraber konjenital diş eksikliğinin erken teşhis

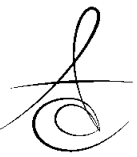


ile tespit edilmesi tedavi planlaması açııından da önem taşımaktadır. Ülkemizde yapılan prevalans çalışmalarının (spesifik bir grup seçilmeden yapılan) sayısının az olması farklı ülkelerle kıyaslama imkanına neden olmaktadır. Her ne kadar bu çalışmalar ile Türk toplumunda yapılan çalışmaların büyük bir kısmı benzer bulgular içerse de kendi toplumumuz içinde farklı bölgelerin kıyaslanması açısından daha fazla çalışmaya intiyaç vardır.

\section{KAYNAKLAR}

1. Morgano Neville BW, Damm DD, Allen CM, Bouquot JE. Oral \& Maxillofacial Pathology. 2 ed. Philadelphia; Wb Saunders Co 2003. p. 372-3.

2. Dhanrajani PJ. Hypodontia: Etiology, Clinical Features, and Management. Quintessence Int 2002; 33: 294-302.

3. Jorgenson RJ. Clinician's View of Hypodontia J Am Dent Assoc 1980; 101: 283-6.

4. Sönmez IŞ, Oba AA. İzole Oligonti: Olgu Sunumu. Cumhuriyet Üniversitesi Diş Hek Derg 2007; 10: 108-12.

5. Akkaya N, Alpaslan S, Kanlı A. Oligodonti: Olgu Bildirimi. Hacettepe Diş Hek Fak Derg 2006; 30: 31-4.

6. Goldenberg $M$, Das $P$, Messersmith $M$, Stockton DW, Patel PI, D'Souza RN. Clinical, Radiographic and Genetic Evaluation of Novel Form of Autosomal-Dominant Oligodontia. J Dent Res 2000; 79: 1469-75.

7. Regezi JA, Sciubba J, Jordan RCK. Oral Pathology -Clinical-Pathologic Correlations $4^{\text {th }}$ ed. Philadelphia: WB Saunders Co 2003. p. 372-3.

8. Nordgarden $\mathrm{H}$, Jensen JL, Storhaug K. Reported Prevalence of Congenitally Missing Teeth In Two Norwegian Counties. Community Dent Health 2002; 19: 258-61.

9. Polder BJ, Van't Hof MA, Van Der Linden FP, Kuijpers-Lagtman AM. A Meta-Analysis of The Prevalence of Dental Agenesis of Permanent Teeth. Community Dent 2004; 32: 217-26.

10. Lynham A. Panoramic Radiographic Survey of Hypodontia in Australian Defence Force Recruits. Aus Dent J 1990; 35: 19-22.

11. Traikiniene G, Ryliskyte M, Kiausatie A. Prevalence of Teeth Number Anomalies In Orthodontics Patients. Stomatologia 2013; 158:45-53
12. Aasheim B, Ögaard B. Hypodontia In 9-year-old Norwegians Related to Need of Orthodontic Treatment. Scand J Dent Res 1993; 101: 25760.

13. Patil S, Doni B, Kaswan S, Rahman F. Prevalance of Dental Anomalies In Indian Population. J Clin Exp Dent 2013;1:183-6.

14. Sheikhi M, Sadeghi MA, Ghorbanizadeh S. Prevalance of Congenitally Missing Permanent Teeth. Dent Res J 2012; 9: 105-11.

15. Tunç EŞ, Koyutürk AE. Karadeniz Bölgesi Çocuklarında Konjenital Daimi Diş Eksikliği Prevalansı. Atatürk Ünv Diş Hek Fak Derg 2006; 16: 37-40.

16. Endo T, Ozoe R, Kubota M, Akiyama M, Shimooka S. A Survey of Hypodontia In Japanese Orthodontic Patients. Am J Orthod Dentofacial Orthop 2006; 129: 29-35.

17. Ezirganlı Ş, Köşger H, Özer K, Kırtay M, Ün E. Konjenital Olarak Eksik Olan İkinci Küçük Azıların Prevalansı. Cumhuriyet Dental J 2010; 13: 4851.

18. Kırzıoğlu Z, Şentut TS, Ertürk MS, Karayılmaz H. Clinical Features of Hypodontia and Associated Dental Anomalies. A Retrospective Study. Oral Diseases 2005; 11: 399-04.

19. Sumer P, Akça T, Köprülü H. Çocuklarda Görülen Dental Anomaliler: Panoromik Radyografik Değerlendirme. Ondokuz Mayıs Üniv Diş Hek Fak Derg 2004; 5: 81-4.

20. Goya HA, Tanaka S, Maeda T, Akimoto Y. An Orthopantomographic Study of Hypodontia in Permanent Teeth of Japanese Pediatric Patients. J Oral Science 2008; 50: 143-50.

21. Silva MR. Radiographic Assessment of Congenitally Missing Teeth in Orthodontic Patients. Int J Paediatr Dent 2003; 13: 112-6.
Yazışma Adresi:
Dr. Ümit CANDAN
İzmir Eğitim Diş Hastanesi,
Başhekim yardımcısı
Sümer Mah, 451 Sk. Konak/IZMİR
Telf: 0.532 .4230047
e-mail: ucandan@hotmail.com, 